\title{
SIMPLE PROOFS OF THE CUSA-HUYGENS-TYPE AND BECKER-STARK-TYPE INEQUALITIES
}

\author{
ZHENG Jie SUN AND LING ZHU
}

Abstract. In this paper, we respectively give some simple proofs of the Cusa-Huygens- and Becker-Stark-type inequalities presented by Chen and Cheung in [9].

Mathematics subject classification (2010): 26D20.

Keywords and phrases: Circular functions, the Cusa-Huygens-type inequalities, the Becker-Stark-type inequalities, new simple proofs of two conjecture by Chen and Chueng.

\section{REFERENCES}

[1] C. Huygens, Oeuvres Completes, 1888-1940, Societe Hollondaise des Science, Haga.

[2] J. SÁndor And M. Bencze, On Huygens' trigonometric inequality, RGMIA Res. Rep. Collect, 8 (3) (2005), Article 14.

[3] L. ZHU, A source of inequalities for circular functions, Comput. Math. Appl., 58 (2009), p. 19982004.

[4] E. NeUmAn AND J. SÁNDOR, On some inequalities involving trigonometric and hyperbolic functions with emphasis on the Cusa-Huygens, Wilker, and Huygens inequalities, Math. Inequal. Appl., 13 (2010), p. 715-723.

[5] C. Mortici, The natural approach of Wilker-Cusa-Huygens inequalities, Math. Inequal. Appl., 14 (2011), p. 535-541.

[6] M. Becker And E. L. StARK, On hierarchy of polynomial inequalities for tan $(x)$, Univ. Beograd. Publ. Elektrotehn. Fak. Ser. Mat. Fiz. No. 602-633 (1978), p. 133-138.

[7] L. Zhu AND J.-K. HuA, Sharpening the Becker-Stark inequalities, J. Inequal. Appl., Article ID 931275 (2010).

[8] L. ZHU, Sharp Becker-Stark-type inequalities for Bessel functions, J. Inequal. Appl., Article ID 838740 (2010).

[9] C.-P. Chen And W.-S. Cheung, Sharp Cusa and Becker-Stark Inequalities, J. Inequal. Appl., doi:10.1186/1029-242X-2011-136.

[10] G. D. Anderson, M. K. VAmanamurthy, And M. Vuorinen, Inequalities for quasiconformal mappings in space, Pac. J. Math., 160 (1) (1993), p. 1-18.

[11] G. D. Anderson, S.-L. Qiu, M. K. Vamanamurthy, and M. Vuorinen, Generalized elliptic integrals and modular equations, Pac. J. Math., 192 (1) (2000), p. 1-18.

[12] I. PINELIS, L'Hospital type results for monotonicity, with applications, Journal of Inequalities in Pure and Applied Mathematics, 3 (1) (2002), article 5, pp. 1-5.

[13] I. PINELIS, "Non-strict" l'Hospital-type rules for monotonicity: intervals of constancy, Journal of Inequalities in Pure and Applied Mathematics, 8 (1) (2007), article 14, pp. 1-8.

[14] L. ZHU, Sharpening Jordan's inequality and the Yang Le inequality, Applied Mathematics Letters, 19 (3) (2006), p. 240-243.

[15] H. AlZER AND S.-L. QIU, Monotonicity theorems and inequalities for the complete elliptic integrals, Journal of Computational and Applied Mathematics, 172 (2) (2004), p. 289-312.

[16] J.-L. LI, An identity related to Jordan's inequality, International Journal of Mathematics and Mathematical Sciences, Article ID 76782, 2006.

[17] M. Abramowitz AND I. A. Stegun, Handbook of Mathematical Functions with Formulas, Graphs, and Mathematical Tables, U. S. National Bureau of Standards, Washington, DC, USA, (1964). 
[18] H. Alzer, Sharp bounds for the Bernoulli numbers, Archiv der Mathematik, 74 (3) (2000), p. 207211.

[19] B. J. MALEŠEvić, One method for proving inequalities by computer, J. Inequal. Appl., Article ID 78691, 2007. 